\title{
A representação de outsiders em Estranhos no Paraíso (1984)
}

\section{Representation of outsiders in Stranger than Paradise (1984)}

Helena Lukianski Pacheco ${ }^{1}$ e Melina Aparecida dos Santos Silva ${ }^{2}$

1 Mestre em Comunicação Social pela Pontifícia Universidade Católica do Rio Grande do Sul (PUCRS). E-mail: helenalukians@gmail.com.

2 Doutora pelo Programa de Pós-Graduação em Comunicação da Universidade Federal Fluminense (UFF). Realiza estágio pós-doutoral no Programa de Pós-Graduação em Comunicação Social da PUCRS. E-mail: melsantos1985@gmail.com. 


\section{Resumo}

O objetivo deste artigo é analisar o filme Estranhos no Paraíso (Stranger than Paradise, 1984), do cineasta estadunidense Jim Jarmusch. Propomos uma reflexão sobre o fato de que, ao longo do século XX, "imagens modelares" do American way of life constituíram uma das várias configurações estadunidenses das relações estabelecidos-outsiders, com o apoio da mídia e da indústria cultural. Desta forma, a análise fílmica de Estranhos no Paraíso terá como um dos principais aportes teóricos a concepção de outsiders. Partiremos da questão: como o filme Estranhos no Paraíso mostra uma representação crítica das relações estabelecidos-outsiders instauradas pelo american way of life?

Palavras-chave

Estabelecidos-Outsiders, Jim Jarmusch, Estranhos no Paraíso.

\section{Abstract}

This article aims to analyze the film Stranger than Paradise (1984), by the American filmmaker Jim Jarmusch. We propose to reflect on the fact that throughout the 20th century "model images") of the American way of life constituted one of the several American configurations of established-outsider relationships, with the support of the media and the cultural industry. Thus, we will mainly base the study of Strangers in Paradise on the conception of outsiders. We will start from the question: how does the film Stranger than Paradise shows a critical representation of the established-outsider relationships established by the American Way of Life?

\section{Keywords}

Established-outsiders; Jim Jarmusch; Stranger than Paradise. 
O cineasta Jim Jarmusch é um outsider (BECKER, 2009) dentro da indústria cinematográfica estadunidense, tanto por sua forma de financiar a produção fílmica (distanciando-se da indústria hollywoodiana) (LACKEY, 2012) como pelas escolhas estéticas e narrativas de seus longas-metragens. Jarmusch iniciou sua carreira em um contexto específico do cinema underground: a cena No Wave, que teve seu epicentro no final dos anos 1970, em Nova York, e foi diretamente influenciada pela música punk, que também ascendia na época. Os filmes feitos dentro desse contexto sociocultural seguiam a lógica punk "do-it-yourself" (DIY), ou seja, faça-você-mesmo. Esse modo de produção, em parte escolhido pela falta de recursos, também tem um caráter ético: "a rejeição dos grandes ideais ligados ao consumismo que o punk oferece mostra que os valores da subcultura são de fato baseados na política" (MORAN, 2010, p. 64, tradução nossa).

Os dois primeiros filmes de Jarmusch tiveram orçamentos ínfimos para os padrões da indústria cinematográfica hollywoodiana. Férias Permanentes (Permanent Vacation, 1980), o seu primeiro longa-metragem, produzido enquanto ele ainda frequentava a New York University, foi feito com aproximadamente doze mil dólares, e Estranhos no Paraíso (Stranger than Paradise, 1984) custou cerca de cem mil dólares (ANDREW, 1999). Os filmes subsequentes foram realizados em coprodução com produtoras estrangeiras, o que também pode ser observado como uma tentativa de se distanciar dos parâmetros da indústria estadunidense. Além disso, conforme aponta Lackey (2012, p. 8), "as perspectivas de seus filmes em relação à cultura americana desestabilizam regularmente a identidade cultural, situando-a em um contexto global".

O termo outsider também se aplica aos personagens de Jim Jarmusch (MIGLIORE; MOUSINHO, 2021), pois eles, em sua maioria, apresentam comportamentos desviantes em relação às normais sociais, ou não se encaixam no modelo preconizado pelo American way of life, um modo de vida que teve grande projeção midiática ao longo do século XX, principalmente após a Segunda Guerra Mundial. Esse modelo está associado a um estilo de vida consumista e, 
portanto, está diretamente relacionado com a expansão econômica do país e a rearticulação após a crise de 1929 (CUNHA, 2017).

De acordo com Robert Sklar, não é que o cinema antes não propagasse mitos e sonhos relacionados ao American way of life, no entanto, a partir da década de 1930, "os cineastas tinham consciência, de um modo mais sofisticado, de seus poderes de fabricar mitos, das suas responsabilidades e das suas oportunidades" (SKLAR, 1975, p. 230). Conforme será analisado neste artigo, as "imagens modelares" (CUNHA, 2017) desse estilo de vida são recorrentes no cinema estadunidense mainstream.

Após explanarmos a respeito dos conceitos que se relacionam diretamente com a filmografia de Jarmusch (American way of life e outsiders), prosseguiremos com a análise fílmica do segundo filme do diretor, Estranhos no Paraíso. A escolha desse longa-metragem justifica-se pelo fato de que a obra apresenta uma faceta dos Estados Unidos que permanece atual, por se tratar de um país que atrai imigrantes em busca de uma vida mais próspera economicamente - é notório o uso do termo "sonho americano" associado à vivência no país (ROOPNARINE, 2008).

A análise fílmica (AUMONT; MARIE, 2009) visa mostrar que as escolhas estéticas demonstram um caráter crítico que se relaciona a uma estratégia menos "voltada para os mecanismos de dominação" (RANCIÈRE, 2009, p. 123). Ainda segundo Rancière, um modelo crítico da arte, posto de forma óbvia, tende à autoanulação. Evitando esse caminho, Jarmusch complexifica as contradições inerentes a qualquer país. A análise parte da seguinte questão: como o filme Estranhos no Paraíso mostra uma representação crítica das relações estabelecidosoutsiders instauradas pelo American way of life? 


\section{American way of life no cinema estadunidense: imagens modelares}

Por meio da TV, do rádio, do cinema e da literatura estadunidense constituíram-se imagens de um país democrático, cujo modo de viver inclui prosperidade econômica, aquisição de casas, automóveis, festas, viagens, eletrodomésticos, tecnologia de ponta, além de valores como "liberdade, sucesso, força, civismo e progresso" (CUNHA, 2017, p. 46). Após a Segunda Guerra, o "sonho americano" passou a ser mais acessível para a classe trabalhadora, incluindo a possibilidade de ter melhores salários, bens de consumo e acesso à educação superior (ORTNER, 2013). No início do século XX, o país consolidou uma imagem de "terra de oportunidades":

Expulsos de seus países pelo crescimento demográfico, modernização agrícola, pobreza e opressão política e religiosa, 25 milhões de imigrantes chegaram aos Estados Unidos, entre 1865 e 1915, um contingente mais de quatro vezes superior ao dos 50 anos anteriores. (KARNAL, 2017, p. 178)

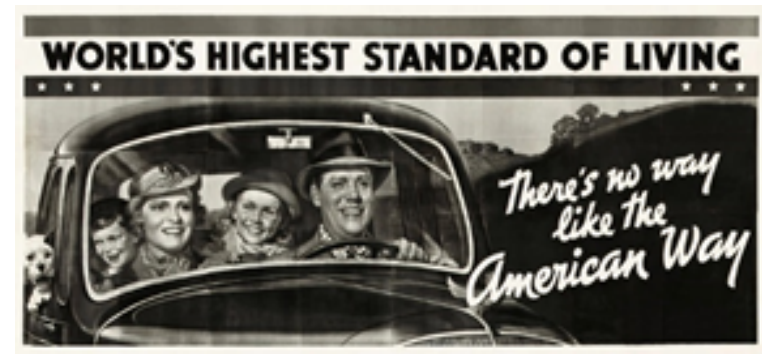

Figura 1: Outdoor publicitário estadunidense de 1973

Fonte: Fine Art America.

A reconstrução econômica dos Estados Unidos após a Grande Depressão de 1929 impulsionou a projeção de imagens "positivas" sobre o American way of life (CUNHA, 2017) (Figura 1). A problematização a respeito dos preceitos do modo de vida americano não é exatamente recente. Na obra do cineasta Frank Capra (1897-1991), esse modelo aparece de forma ambígua: "no filme A Felicidade Não se Compra (It's a Wonderful Life, 1946), é possível encontrar 
um retrato crítico de valores - como acomodação, usura, provincianismo, religiosidade - que se dissimula nos acordes de sentimentos nobres e honrados" (CUNHA, 2017, p. 78).

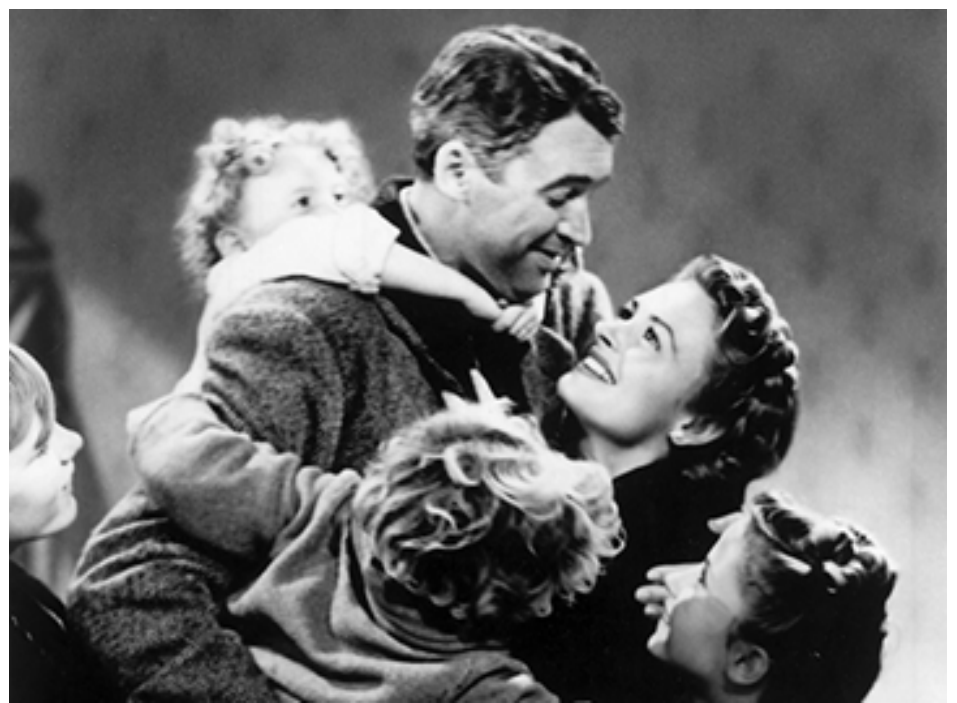

Figura 2: A Felicidade Não se Compra

Fonte: frame do filme A Felicidade Não se Compra.

Nesse filme, no entanto, a união familiar, um dos valores do American way of life, é um ideal reforçado como desejável para o cidadão convencional. A desconstrução da família como um núcleo idílico de bons sentimentos aparece de forma exemplar no filme Beleza Americana (American Beauty, Sam Mendes, 1999). No longa-metragem, Lester Burham é um homem de meia-idade da classe média com uma vida aparentemente bem-estabelecida com sua esposa e sua filha, Carolyn e Jane. Na verdade, ele se sente frustrado com o casamento e o emprego, e passa a se interessar pela amiga de sua filha adolescente.

Em Beleza Americana, a família tenta inicialmente manter um "ar de normalidade", apesar de problemas que rompem com a idealização do ambiente familiar, como infidelidade conjugal e frustrações profissionais. O desfecho trágico está de acordo com a impossibilidade de comportamentos desviantes dentro desse modelo: "o final do filme, ao contrário do que se poderia prever, não remete à restauração da ordem, mas às possíveis consequências de algumas escolhas 
e comportamentos, atitudes essas vistas como transgressoras ou desviantes" (COELHO, 2014, p. 94).

Beleza Americana é exemplo interessante de filme realizado dentro da indústria hollywoodiana que possui um viés crítico a respeito do American way of life, pois visões desafiadoras em relação a questões sociais estão mais associadas ao cinema independente americano (KING, 2005). No entanto, observa-se que a mensagem final parece bastante assertiva em sugerir que não há como "sobreviver" fora desse modelo de vida.

Dentro do cinema indie estadunidense, o longa-metragem Pequena Miss Sunshine (Little Miss Sunshine, Valerie Faris; Jonathan Dayton, 2006) também se contrapõe às imagens modelares que incluem "as famílias unidas, os amigos de bairro, o sonho conquistado da faculdade, a hipoteca que possibilitaria acesso à casa própria, os filhos, a comida congelada, eventualmente uma profissão glamourosa [...]" (CUNHA, 2017, p. 79).

No filme, Olive é uma criança que deseja participar de um concurso de beleza chamado Pequena Miss Sunshine. A família decide viajar com Olive para a realização do concurso, e ao longo do percurso passa-se a conhecer melhor a sua família disfuncional, que inclui um tio homossexual e suicida e um avô usuário de cocaína.

Na narrativa do filme, observa-se como cada integrante da família está inserido em grupos outsiders, embora alguns familiares defendam as normas convencionais da família estadunidense. Olive não se enquadra nos ditames estéticos do júri. O tio de Olive é um outsider pelo olhar conservador do status quo, visto que sua orientação sexual não segue a heteronormatividade. O pai de Olive também não se encaixa nos padrões profissionais e de meritocracia que defende. Pequena Miss Sunshine problematiza, portanto, o ideal do American way of life que opõe vencedores de perdedores e corrobora, dessa forma, com a construção de uma sociedade excludente e composta por pessoas frustradas.

A singularidade da crítica na filmografia de Jim Jarmusch também está no fato de que o diretor adota outra estratégia para mostrar um lado menos promissor 
do American way of life. A "instituição" família está praticamente ausente na sua filmografia, ou é apresentada de forma fragmentada e muito distante do que seria um modelo positivo dentro do American way of life: a família fordista típica consistia em um homem trabalhador, uma esposa dona-de-casa e um ou mais filhos (COOPER, 2017).

Em vez de se ater a traços disfuncionais de personagens que tentam se adaptar ao american dream, os filmes de Jim Jarmusch apresentam personagens pouco ambiciosos (outsiders). Além disso, na narrativa fílmica, destacam-se "tempos mortos", distanciando-se da lógica do cinema ligado a situações sensóriomotoras, ou seja, que possuem uma relação de causa e efeito (DELEUZE, 1990).

Os olhares de Jarmusch estão correlacionados à própria trajetória dos estudos de outsiders nas Ciências Sociais. Os sociólogos estadunidenses nas décadas de 1950 e de 1960 estudavam as configurações dos outsiders focandose nas análises de ações de infração variadas e outras maneiras de transgredir normas socialmente aceitas, além de investigarem os motivos pelos quais esses transgressores não se inseriram nos valores sociais predominantes. A partir dos estudos de Howard Becker (2009), o termo passa a abranger a questão do desvio para além da criminologia.

\section{Outsiders}

Neiburg em A sociologia das relações de poder de Norbert Elias - apresentação da edição brasileira de Os Estabelecidos e Outsiders (2000) - chama a atenção para o significado dos termos establishment e established, que costumam ser usados para nomear grupos sociais e sujeitos que estão inseridos em posições de poder consolidadas. Quando um grupo social é referenciado como establishment, observa-se que esse grupo se reconhece como poderoso e superior, ao mesmo tempo que ostenta os ideais de "tradição, autoridade e influência" (NEIBURG, 2000, p. 7).

O outro lado da moeda é o termo outsiders, ou seja, um conjunto de pessoas considerado não coeso, com relações sociais menos intensas e de caráter 
duvidoso na concepção do modelo moral defendido pelo establishment. Esta forma de enunciação, criada pelo establishment para descrever o grupo social excluído de suas relações de poder, revela como o termo no plural reforça a indefinição de informações demográficas e de perfil sociológico dos sujeitos presentes nesta delimitação específica. Essa indefinição e negação do outro não é aleatória. Ambas permitem que a identidade do establishment continue a ser defendida em relação à presente ameaça que os modos de vida dos outsiders representam para suas relações sociais.

Esses processos de construção de identidades entre establishment e outsiders são atravessados pelas formas de representação dos sujeitos em relação ao olhar do outro, dividindo os atores sociais entre nós e eles (WOODWARD, 2000). Como a identidade e a diferença dependem da representação para adquirir sentido, elas também estão inseridas em um processo de inclusão e de exclusão através do discurso. A identidade e a diferença são construções de linguagem, criadas em contextos culturais e sociais, tornando-as marcadas pela instabilidade da própria representação discursiva:

\footnotetext{
Elas não são só definidas como também impostas, elas não convivem harmoniosamente, lado a lado, em um campo sem hierarquias; elas são disputadas. A identidade e a diferença estão, pois, em estreita conexão com a relação de poder: o poder de definir a identidade e de marcar a diferença não pode ser separado das relações mais amplas de poder. A identidade e a diferença não são, nunca, inocentes. (WOODWARD, 2000, p. 81)
}

O que motivou a pesquisa de Norbert Elias e John Scotson (2000) na comunidade industrial de Winston Parva é a relação antagônica entre establishment X outsiders presente entre vizinhos com perfil socioeconômico relativamente homogêneo. Embora as diferenças socioeconômicas entre moradores fossem praticamente inexistentes no olhar dos pesquisadores, a percepção dos moradores de Winston Parva demonstrava o contrário. Naquela comunidade industrial, existia um grupo que se identificava e era identificado pelos demais como estabelecido e um coletivo de moradores que não possuía os requisitos para ser aceito pelo 
mesmo grupo. As interações sociais entre ambos os grupos giravam em torno da diferença de tempo de permanência no local. Os outsiders de Winston Parva, moradores mais novos da comunidade, internalizaram e replicaram essa percepção do establishment em relação a si, contribuindo para a manutenção dessa relação de poder instaurada por meio do discurso da tradição e dos valores prezados pelos moradores mais antigos.

Elias e Scotson (2000) procuraram compreender as condições e as estratégias em que os estabelecidos estigmatizavam o outro grupo de moradores recémchegados em Winston Parva. Neste caso, a própria dinâmica de estabelecidosoutsiders em um nível macro agrega os mesmos tipos de relações de força desigual desencadeados em Winston Parva. O grupo estabelecido se considerava o núcleo superior e bem-sucedido da vizinhança, mantendo apenas relações profissionais com os novos moradores. Os sistemas de estigmatização dos outsiders pelo establishment englobavam desde a exclusão total deles em eventos de socialização até o uso de fofocas e outras nomeações depreciativas para se referirem aos modos de vida dos novos moradores (ELIAS; SCOTSON, 2000).

Em um nível social macro, a manutenção de status superior de um grupo em relação ao outro pode ser observada nas formas de envergonhar os outsiders por meio de termos como "gringo", "crioulo" e "sapatão" (ELIAS; SCOTSON, 2000, p. 27). Elias e Scotson (2000) apontam que as relações estabelecidos-outsiders não possuem dinâmicas ligadas à diferença racial ou étnica e que o uso destes termos para compreender as relações de poder consiste em uma forma de negação do contexto histórico macro:

Parece que adjetivos como "racial" ou étnico, largamente utilizados nesse contexto, tanto na sociologia quanto na sociedade em geral, são sintomáticos de um ato ideológico de negação. Ao empregá-los, chama-se a atenção para um aspecto periférico dessas relações (por exemplo, a cor da pele), enquanto se desviam os olhos daquilo que é central (por exemplo, os diferenciais de poder e a exclusão do grupo menos poderoso dos cargos com maior potencial de influência). (ELIAS; SCOTSON, 2000, p. 32) 
O argumento dos sociólogos defendido acima aponta uma questão sensível e que foi tratada através do universalismo europeu (WALLERSTEIN, 2006) presente na academia. No caso desta passagem, defendemos a necessidade de se considerar como a intersecção de raça, classe social, faixa etária, nacionalidade e gênero sexual constrói formas de opressão em relação a grupos sociais específicos (COLLINS, 2016; WYNTER, 2003). Caso adotássemos o universalismo europeu nas relações estabelecidos-outsiders, desvincularíamos a diferença colonial e as formas de opressão naturalizadas em relação aos grupos subalternizados, que basearam - e ainda baseiam - a política, a economia, a cultura e as estruturas sociais estadunidenses.

De outra forma, se seguíssemos a perspectiva universalizante de estabelecidosoutsiders de Elias nos deslocaríamos das próprias tensões sociais vivenciadas pelos grupos subalternizados presentes nos filmes de Jarmusch. A publicação do livro Outsiders: estudos de sociologia do desvio (BECKER, 2009) desenvolveu um outro olhar em relação ao desvio social demonstrando que os desviantes não estavam somente inseridos na área da Criminologia. Becker demonstrou como os grupos sociais definem determinadas ações como incorretas e que não devem ser violadas. Desta forma, uma das dinâmicas da relação estabelecidos-outsiders seria as relações de poder instauradas pelo grupo dominante para evitar as transgressões de suas normas.

Becker (2009, p. 15) aprofunda a compreensão de sujeitos à margem das normas sociais. Para tanto, o sociólogo estadunidense explora como grupos qualificados de outsiders pelo establishment - como os consumidores de maconha e os músicos de jazz - têm suas próprias regras de interação social e seus conceitos de normalidade. Desta forma, Becker (2009) demonstra que o desvio não poderia ser interpretado somente como uma patologia, mas que deveríamos prestar atenção na interação entre o sujeito desviante e as formas de reação do "outro" (BECKER, 2009, p. 21).

Becker (2009) observa como grupos outsiders das cenas do jazz de Chicago desenvolvem práticas culturais para se protegerem da influência de ouvintes de 
jazz convencionais. As fronteiras simbólicas entre os instrumentistas de jazz e os públicos - considerados "quadrados" e não detentores de conhecimentos da produção musical - são estabelecidas desde a posição distanciada dos palcos de shows ao vivo até a constituição de discursos dicotômicos entre a autenticidade do jazz e a cooptação da música comercial. A etnografia de Becker com os instrumentistas de jazz é sensível às configurações de estabelecidos-outsiders no ambiente familiar, na indústria fonográfica e nos próprios circuitos musicais do jazz nos quais os artistas transitam.

Para demonstrar como a sociedade apresenta muitos grupos sociais e que cada um segue suas convenções, Becker (2009) acompanha formas de comportamento desviantes, como as dos consumidores de maconha, que também transitam na cena do jazz. Becker (2009) foca em três eixos de pensamento: a) as percepções que os músicos têm de si mesmos e dos não-músicos com quem trabalham e os conflitos que Ihes parecem inerentes a essa relação (p. 94-104); b) o consenso básico relacionado às reações de músicos comerciais e de jazz diante desse conflito (p. 101); c) os sentimentos de isolamento que os músicos experimentam em relação à sociedade mais ampla e o modo como se segregam do público e da comunidade (p. 105). No cinema de Jim Jarmusch, a questão do não-pertencimento não se estabelece de forma consciente por parte dos personagens outsiders; por outro lado, é perceptível para o espectador, conforme analisaremos na próxima seção.

\section{Estranhos no Paraíso}

Jim Jarmusch não é um cineasta de fases bem demarcadas, embora alguns pontos de contato possam ser observados conforme o período em que os filmes foram feitos. Nos três primeiros filmes da década de 1980, os longas-metragens aproximam-se em termos da fotografia, e Jarmusch parece mais interessado em mostrar a falta de perspectiva de imigrantes europeus nos Estados Unidos.

A partir do filme Mystery Train (1989), podemos observar que Jarmusch passou a incluir em seus filmes personagens oriundos de outros lugares além 
da Europa: no primeiro dos três episódios desse longa-metragem, um casal de japoneses visita a cidade de Memphis, localizada no estado do Tennessee (EUA). Na obra subsequente, há uma amplificação ainda maior da representação da diversidade cultural: Uma Noite Sobre a Terra (Night on Earth, 1991) é um filme constituído por cinco episódios filmados em metrópoles diferentes (Los Angeles, Nova York, Paris, Roma e Helsinki). Há manifestações de xenofobia, racismo e machismo nos rápidos contatos entre desconhecidos (motoristas e passageiros oriundos de diferentes países se encontram em cada segmento do longa-metragem). Os filmes mais recentes de Jim Jarmusch apresentam personagens do universo fantástico (os vampiros de Amantes Eternos e os zumbis de Os Mortos não Morrem) -, também excluídos da sociedade "normal".

A estética outsider se constrói para além do comportamento dos personagens. Na primeira "fase" de Jim Jarmusch, podemos observar que a fotografia se opõe à estética colorida da new wave, gênero musical predominante na época. A música era muitas vezes caracterizada por novos sons eletrônicos de sintetizadores, e o visual das bandas era composto por vistosas roupas de nylon (MCKNIGHT-TRONTZ, 2005). Ao optar por jazz como trilha sonora (ou rock dos anos 1950, no caso de Estranhos no Paraíso), há um afastamento da década de 1980 na questão da sonoridade e na valorização desses outsiders da indústria fonográfica estabelecida.

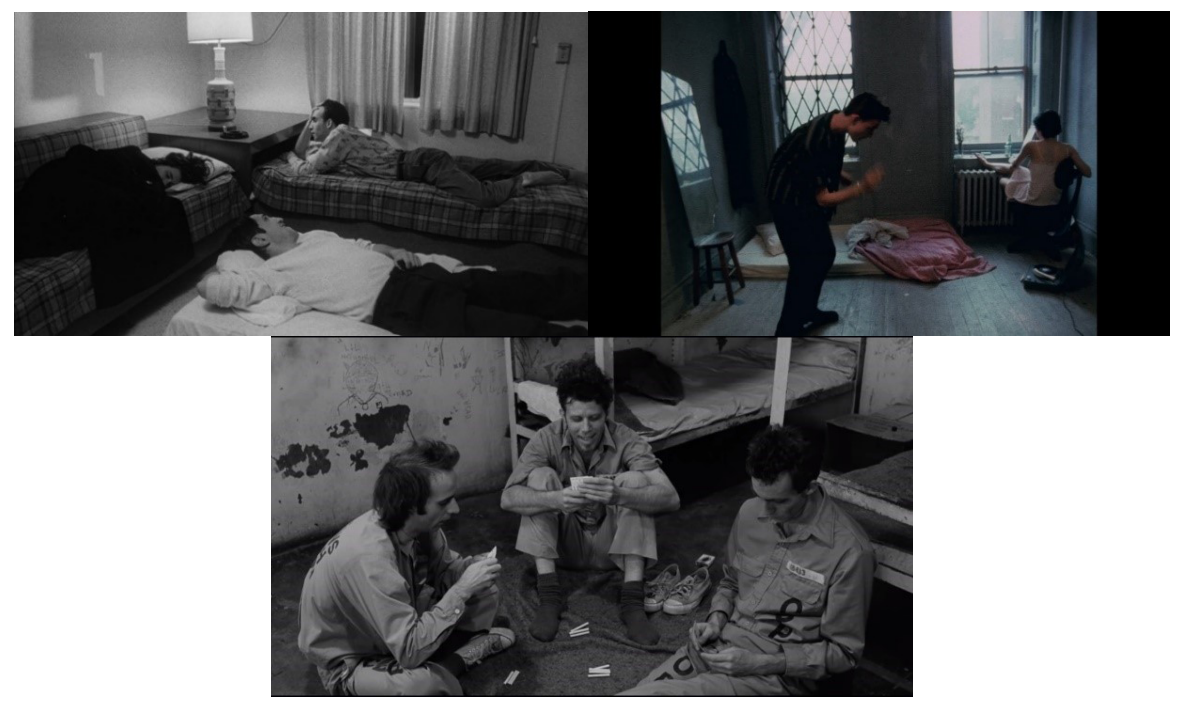


Figura 3: Fotogramas de Férias Permanentes (esq.),

Estranhos no Paraíso (dir.) e Down by Law

Fonte: Férias Permanentes (1980), Estranhos no Paraíso (1984) e Down by Law (1986).

Além disso, é importante pontuar que Estranhos no Paraíso foi lançado em um momento de aceleramento do uso da imagem, marcado pela criação do canal MTV (Music Television), em 1981, que exibia vídeos musicais de curta duração muitas vezes influenciados pela publicidade (CORRÊA, 2007). Considerando esse contexto, o filme surgiu como um completo dissenso ao que estava em voga naquele momento. Compreendemos o conceito de dissenso para além de "oposição ou discordância", considerando a visão de Rancière a respeito da relação entre estética e política. Por esse viés, o dissenso relaciona-se com uma potência crítica, "no sentido de que novas formas de circulação da palavra, da exposição do visível e de produção dos afetos determinam capacidades novas, em ruptura com a antiga configuração do possível" (2012a, p. 63).

A construção da "imagem" outsider abarca a questão do espaço e da narrativa. As práticas artísticas permitem uma reconfiguração do espaço comum, em uma abordagem que possibilita "um recorte dos tempos e espaços, [...] da palavra e do ruído que define ao mesmo tempo o lugar e o que está em jogo na política como forma de experiência" (RANCIÈRE, 2009, p. 16).

A narrativa de Estranhos no Paraíso é dividida em três partes: The New World (O Novo Mundo), One Year Later (Um Ano Depois) e Paradise (Paraíso). Na primeira, o jovem Willie recebe, inicialmente a contragosto, a visita de sua prima Eva, recém-chegada de Budapeste. Um ano depois, eles se reencontram em Cleveland juntamente com Eddie, amigo de Willie. Por fim, os três partem para a Flórida.

O desencanto com o american dream (sonho americano) pode ser representado de diversas formas. Há um tipo de cinema que mostra os "estigmas da dominação", no entanto, há maneiras menos óbvias de se mostrar relações entre oprimidos e opressores: em um "regime estético da arte" que se distancia 
de uma produção artística com fins sociais bem definidos podemos apreender "novas formas de subjetivação política" (RANCIÈRE, 2012a, p. 81).

O título da primeira parte remete a uma "terra prometida" de progresso e de felicidade, um novo mundo cheio de oportunidades. Assim que Eva chega a Nova York, ela caminha por partes da cidade que mostram o resultado da crise fiscal de 1970 que assolou a cidade: "a reestruturação capitalista e a desindustrialização vinham havia anos corroendo a base econômica da cidade, e a rápida suburbanização deixara boa parte do centro empobrecida" (HARVEY, 2008 , p. 54). Esses problemas se somavam a um contexto mais amplo, como a crise do petróleo de 1973, o escândalo de Richard Nixon (1968-74), e a derrota na Guerra do Vietnã (1975) (HOBSBAWM, 1995).

No filme, Eva passa por uma rua em que se lê, escrito em grafite: "US out of everywhere - yankee go home". Anteriormente usada durante a Guerra de Secessão, a frase "yankee go home" passou a ser utilizada indiscriminadamente contra os estadunidenses como forma de protesto. A primeira frase (US out of everywhere) atesta que se trata de uma manifestação anti-imperialista. Desde 1945, os Estados Unidos exercem um papel de "império indireto": "os Estados Unidos desfrutam de maior poder global do que qualquer outro Estado. Dominam o mundo não apenas militarmente, mas também em grande parte cultural e economicamente..." (LIEVEN, 2004, p. 2, tradução nossa).

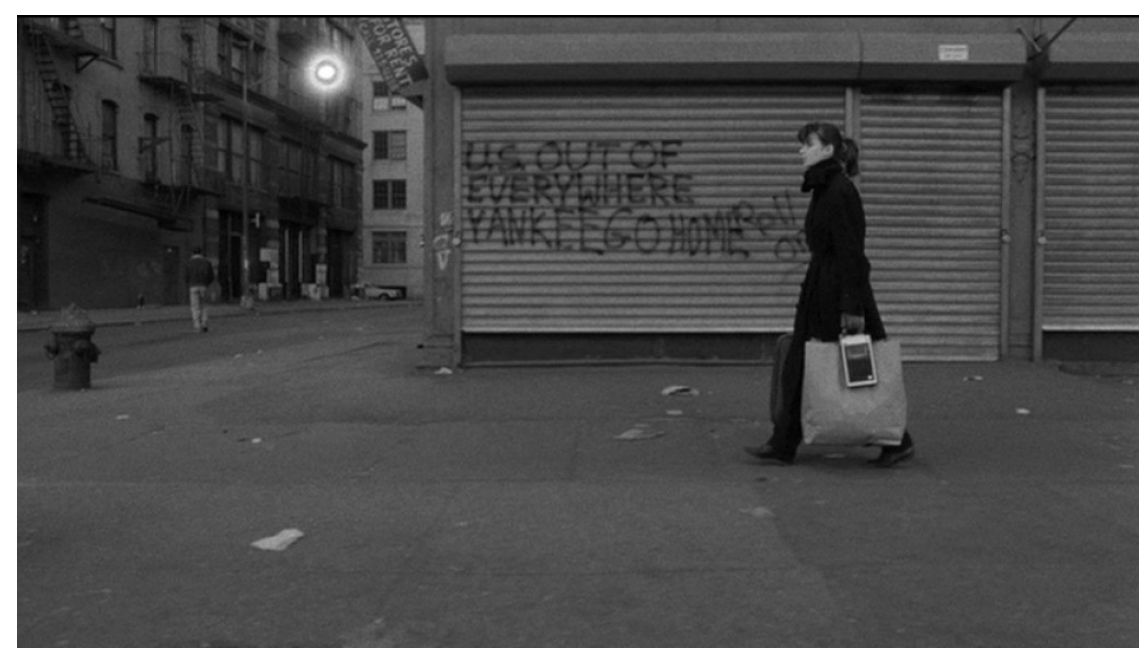

Figura 4: Estranhos no Paraíso 
Fonte: frame do filme Estranhos no Paraíso.

Mesmo em um momento de crise econômica e de acirramento do conservadorismo político na década de 1980, os Estados Unidos não deixaram de representar um "novo mundo" para imigrantes, como os personagens húngaros Eva e Willie. Willie, que na verdade se chama Bela, não suporta o seu nome de batismo e não gosta que seus parentes conversem com ele em húngaro. Quando seu amigo Eddie descobre que ele é da Hungria, Willie faz questão de frisar: "eu sou tão americano quanto você".

A sua "inserção" na sociedade norte-americana aparece de algumas formas no filme. Willie quase nada tem dos predicados de "cidadão exemplar" (CUNHA, 2017), como uma família nos moldes "pai, mãe e filhos", emprego e poder aquisitivo para comprar produtos novos. No entanto, ele exalta o que detém desse "novo mundo", como se evidencia na cena em que o personagem fala com orgulho da comida congelada (apropriadamente chamada TV Dinner) que costuma consumir, para espanto da sua prima húngara.

Há uma sequência do filme em que podemos observar com mais veemência a inserção parcial de Willie na sociedade estadunidense. No primeiro segmento do filme (O Novo Mundo), Willie e Eva assistem a um jogo de baseball. Ela inicialmente parece pouco interessada, mas ainda assim ele explica a função do quarterback (jogador da equipe ofensiva) no jogo. Quando Eva faz uma pergunta, Willie não sabe o que responder e se irrita, dizendo "apenas assista ao jogo". Esse plano é intercalado por uma tela preta que dura cerca de dois segundos. No próximo plano, eles continuam acompanhando à programação da TV, mas trata-se de um filme de ficção científica, conforme infere-se pelos diálogos e barulhos de "nave espacial". Novamente, a tela de transição preta aparece e a cena é retomada mostrando os dois assistindo a um desenho animado (de novo infere-se pelo som). 
O estilo singular de Jim Jarmusch é construído por meio de uma articulação entre espaços vazios e uma narrativa mais convencional. Desde o seu primeiro filme, Férias Permanentes (Permanent Vacation, 1980), podemos observar que Jarmusch inclui em seus filmes cenas em que seus personagens estão em deslocamento, seja caminhando, dirigindo ou andando de trem, como em Mystery Train (1989) e Dead Man (1995). Ao alongar a duração dessas cenas, Jarmusch afasta-se do cinema de "imagem-ação", que "supõe uma ação que a desvele, ou suscita uma reação que se adapte a ela ou a modifique" (DELEUZE, 1990, p. 14). Também nesse sentido, de uma forma mais simbólica, o cinema de Jarmusch está distante de uma lógica associada ao American way of life, que pressupõe um avanço em direção ao progresso. Em Estranhos no Paraíso, com as intercalações de telas pretas, o espectador pode se ater a mudanças sutis nos personagens, sentindo a passagem do tempo:

Da erotização das bordas do quadro ao jogo das distâncias, em meio a variações de intensidade, passagens, ausências, silêncios, movimentos reversíveis, estados de transição, fases da metamorfose - todas as mudanças de ritmo que vêm perfurar a cena, bem como o sujeito/ espectador posto aí, transformam toda "mensagem" em objeto difícil de apanhar, perigoso, pouco controlável. (COMOLLI, 2015, p. 174) 

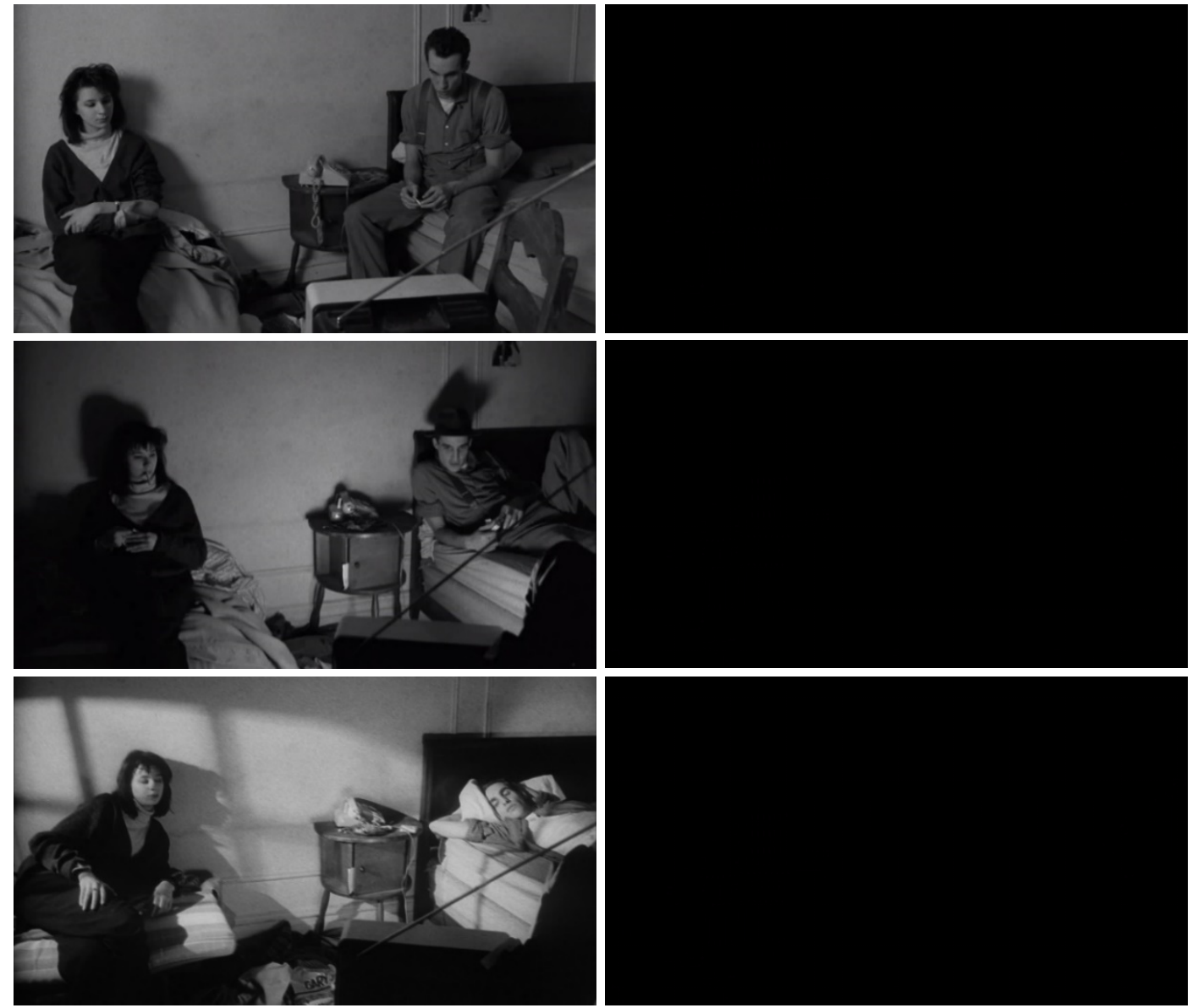

Figura 5: Fotogramas de Estranhos no Paraíso

Fonte: frame do filme Estranhos no Paraíso.

Nesse sentido, o pensamento de Comolli alinha-se às ideias de Rancière propostas em O Espectador Emancipado: "há uma estética da política no sentido de que os atos de subjetivação política redefinem o que é visível, o que se pode dizer dele e que sujeitos são capazes de fazê-lo" (2012a, p. 63). Os frequentes planos de câmera fixa no cinema de Jim Jarmusch opõem-se à estética do modo de vida neoliberal:

A cultura visual contemporânea está amplamente sincronizada com o pulso do neoliberalismo: a proliferação e circulação de imagens 24/7 em várias mídias é estruturalmente integrada à política econômica da velocidade. (JARVIS, 2019, p. 9, tradução nossa) 
Tendo em vista o viés de Dardot e Laval (2016, p. 16), para além de uma doutrina socioeconômica, o neoliberalismo "produz certos tipos de relações sociais, certas maneiras de viver, certas subjetividades".

A sociedade atual é caracterizada por nos expor constantemente a uma espécie de caleidoscópio de imagens provenientes de diversos dispositivos móveis, computadores e televisões. De que forma poderíamos refletir sobre a sociedade com a atenção fragmentada em vários focos? Podemos considerar, portanto, que "o cinema lento oferece não apenas uma estética alternativa, mas uma intervenção biopolítica no trabalho de percepção" (JARVIS, 2019, p. 24, tradução nossa).

O ritmo lento, no caso de Jarmusch, é "uma estratégia própria de uma operação artística" (RANCIÈRE, 2012, p. 121), que se alinha à proposta de mostrar os Estados Unidos de uma forma menos interessante para outsiders. A construção estética não acontece por meio de um "choque de elementos heterogêneos" (RANCIÈRE, 2012a, p. 69), mas sim através de uma relação sutil, como em um dos planos mais conhecidos do filme em que Eva, Eddie e Willie chegam à Flórida. A mensagem "Welcome to Florida" escrita em um muro está integrada à paisagem de forma "realista", basta a falta de cor para sugerir uma sensação de apatia na vida dos personagens.

A opção por mostrar os personagens viajando para a Flórida na última parte do filme não parece ter sido arbitrária. Nesse estado surgiu o New Urbanism, um movimento que visava à construção de comunidades semelhantes aos condomínios de classe média que conhecemos hoje:

A primeira experiência mais visível desse movimento foi a cidade de Seaside, na Flórida, inaugurada em 1981, que atraiu, segundo Robert Davis seu fundador e participante ativo do Congress of New Urbanism - muitos compradores à procura de uma combinação de novas casas, urbanismo tradicional e um sentimento de comunidade.[...] Sua paisagem tornou-se mundialmente conhecida quando serviu de cenário de uma amável, tranquila, pequena e "perfeita" cidade para o filme "The Truman Show", onde Truman Burbank, interpretado por Jim Carrey, vivia aparentemente 
feliz, até descobrir fazer parte de um filme da vida real transmitido pela TV, no qual era o protagonista. (FRÚGOLI, 2001)

No decorrer do século XX, nos Estados Unidos, foram criados subúrbios destinados às classes médias, que buscavam fugir de "problemas urbanos" em áreas centrais, como a violência e a deterioração. Trata-se da "lógica do condomínio", um modo de vida que parece idílico, mas que faz o indivíduo submergir em uma ilusão:

A psicanálise nos ensina a reconhecer com suspeita tais produções da cultura, que acenam com uma região de extraterritorialidade protegida, um espaço abrigado onde se concentraria a realização do prazer retinto de liberdade hedonista. Aprendemos com a experiência neurótica que o passo seguinte à montagem de uma fantasia de tal expressão é o estranho sentimento de servidão que nos acorrenta à repetição de uma mesma rotina fantasmática. (DUNKER. 2011, p. 1)

O filme Estranhos no Paraíso mostra uma oposição ao artificialismo excludente de lugares como Seaside. Os personagens procuram alguma emoção "do lado de fora" e encontram uma Flórida cinzenta, esvaziada de diversidade. Podemos dizer, portanto, que não se trata simplesmente de uma metáfora que permanece atual, mas de uma imagem que foi potencializada com a crescente expansão da construção de condomínios no mundo globalizado.

\section{Considerações finais}

Imagens modelares dos Estados Unidos, projetadas pela mídia, ajudaram a reforçar os valores do American way of life. Em seus filmes, Jim Jarmusch adota uma estratégia artística que não aparece como um simples contraponto a esse modelo, e dessa forma, afasta-se da representação de uma visão maniqueísta sobre os outsiders nos Estados Unidos.

Ao evitar um viés dicotômico, a problematização acerca da vivência dos imigrantes nos Estados Unidos em Estranhos no Paraíso se torna mais densa. Os personagens não expressam sentimentos de segregação e/ou isolamento como os músicos de jazz descritos pelo sociólogo Howard Becker. Ainda assim, eles 
aparecem em cena na maior parte do tempo sozinhos, permitindo ao espectador perceber que de fato os outsiders estão à parte do resto da sociedade.

Ainda que Willie se considere um estadunidense por viver no país e aderir aos hábitos culturais locais, ele não tem possibilidades concretas de acessar o "sonho americano". Através da construção estética, apreende-se uma visão condizente ao desencantamento que é a vida para imigrantes como os primos húngaros. Mesmo quando eles buscam algo novo em seus deslocamentos pelos Estados Unidos, acabam encontrando sempre as mesmas paisagens cinzentas. A análise de filmes como Estranhos no Paraíso, assim como de outros longas-metragens de Jim Jarmusch, pode ser continuamente desdobrada na medida em que a questão da imigração (e suas consequências sociais) permanece sendo um problema contemporâneo.

No imaginário criado por Jarmusch, temos a tensão entre as pessoas que migraram de África, da Ásia, das Américas e do Oriente Médio para os Estados Unidos em busca das condições de vida publicizadas pelo American way of life. Com as variadas fases de migrações, a nação estadunidense apresenta a complexidade das sociedades multiculturais, ao mesmo tempo que seus modos de vida idealizados pelo consumo posicionam os migrantes como outsiders do status quo estabelecido pelo American way of life. A correlação entre estabelecidos e outsiders nos filmes de Jarmusch evidencia "os desafios de uma efetiva integração social e desenvolvimento econômico que impedem a solidariedade étnica" (ROOPNARINE, 2008, p. 153). De forma mais direta, Jarmusch problematiza o modo como o American way of life e a glória de Hollywood romantizam e/ou ignoram "evidências dos conflitos sociais que promovem uma mentalidade outsiders/insiders" entre os migrantes (ROOPNARINE, 2008, p. 153).

\section{Referências}

ANDREW, G. Stranger than Paradise: Maverick film-makers in recent American cinema. Nova York: Limelight, 1999. 
AUMONT, J.; MARIE, M. A análise do filme. Lisboa: Texto \& Grafia, 2009.

BECKER, H. Outsiders: estudos de sociologia do desvio. Rio de Janeiro: Zahar, 2009.

COELHO, P. Desconstruindo a Beleza americana: discursos sobre família no cinema. Domínios da Imagem, Londrina, v. 8, n. 15, p. 98-122, 2014.

COLLINS, P. H. Aprendendo com a outsider within. A significação sociológica do pensamento feminista negro. Revista Sociedade e Estado, Brasília, DF, v. 31, n. 1, p. 99-127, 2016. DOI: https://doi.org/10.1590/S0102-69922016000100006.

COMOLLI, J. L. O espelho de duas faces. In: YOEL, G. (org.). Pensar o cinema: imagem, ética e filosofia. São Paulo: Cosac Naify, 2015. p. 165-203.

COOPER, M. Family values: between neoliberalism and the new social conservatism. Nova York: Zone Books, 2017.

CORRÊA, L. J. A. Breve história do videoclipe. CONGRESSO BRASILEIRO DE CIÊNCIAS DA COMUNICAÇÃO DA REGIÃO CENTRO-OESTE, 8., 2007, Cuiabá. Anais [...]. Cuiabá: Intercom, 2007. p. 1-15. Disponível em: https://bit.ly/3ILaJZP. Acesso em: 9 dez. 2021.

CUNHA, P. R. F. American way of life: representação e consumo de um estilo de vida modelar no cinema norte-americano dos anos 1950. 2017. Tese (Doutorado em Comunicação e Práticas de Consumo) - Escola Superior de Propaganda e Marketing, São Paulo, 2017.

DARDOT, P.; LAVAL, C. A nova razão do mundo: ensaio sobre a sociedade neoliberal. São Paulo: Boitempo, 2016. 
DELEUZE, G. A imagem-tempo. São Paulo: Brasiliense, 1990.

DUNKER, C. I. L. A lógica do condomínio ou: o síndico e seus descontentes. Leitura flutuante. Revista do Centro de Estudos em Semiótica e Psicanálise, São Paulo, v. 1, p. $1-8,2011$.

ELIAS, N.; SCOTSON, J. Os estabelecidos e os outsiders: sociologia das relações de poder a partir de uma pequena comunidade. Rio de Janeiro: Jorge Zahar, 2000.

FRÚGOLI JR., H. Celebration: a busca da cidade perfeita e a vida real. EURE, Santiago, v. 27, n. 81, p. 123-127, 2001.

HARVEY, D. O neoliberalismo: história e implicações. São Paulo: Loyola, 2008.

HOBSBAWM, E. Era dos extremos: o breve século XX: 1914-1991. São Paulo: Companhia das Letras, 1995.

JARVIS, B. "You'll never get it if you don't slow down, my friend": towards a rhythm analysis of the everyday in the cinema of Jim Jarmusch and Gus Van Sant. Journal of American Studies, Cambridge, v. 54, n. 2, p. 385-406, 2019. DOI: https://doi.org/10.1017/S0021875818001421.

KARNAL, L. História dos Estados Unidos: das origens ao século XXI. São Paulo: Contexto, 2007.

KING, G. American Independent Cinema. Nova York: I. B. Tauris, 2005.

LACKEY, E. Arbitrary reality: the global art cinema of Jim Jarmusch. 2012. Dissertação (Mestrado em Artes) - University of Kansas, Kansas, 2012. 
LIEVEN, A. America right or wrong: an anatomy of american nationalism. Nova York: Oxford University Press, 2004.

MCKNIGHT-TRONTZ, J. This ain't no disco: new wave album covers. São Francisco: Chronicle Books LLC, 2005.

MIGLIORE, R; MOUSINHO; L. Outsiders na telona: alteridade e dialogismo em ghost dog e no cinema de Jim Jarmusch. ANIMUS - Revista Interamericana de Comunicação Midiática, Santa Maria, v. 18 n. 38, p. 111-129, 2019.

MORAN, I. P. Punk: the do-it-yourself subculture. Social Sciences Journal, Danbury, v. 10 , n. 1 , p. 58-65, 2010.

NEIBURG, F. Apresentação à edição brasileira. In: ELIAS, N.; SCOTSON, J. Os estabelecidos e os outsiders: sociologia das relações de poder a partir de uma pequena comunidade. Rio de Janeiro: Jorge Zahar, 2000. p. 7-12.

ORTNER, S. B. Not Hollywood: independent film at the twlight of the American dream. Londres: Duke University Press, 2013.

RANCIÈRE, J. A partilha do sensível. São Paulo: Editora 34, 2009.

RANCIÈRE, J. As distâncias do cinema. Rio de Janeiro: Contraponto, 2012.

RANCIÈRE, J. O espectador emancipado. São Paulo: Martins Fontes, 2012a.

ROOPNARINE, L. United States Virgin Islands migration. Social and Economic Studies, v. 57, n. 3/4, p. 131-156, 2008. São Francisco: Chronicle Books LCC, 2005.

SKLAR, R. História social do cinema americano. São Paulo: Cultrix, 1975. 
WALLERSTEIN, I. European Universalism: the rhetoric of power. Londres: New Press, 2006.

WOODWARD, K. Identidade e Diferença: uma introdução teórica e conceitual. In: SILVA; T., HALL, S; WOODWARD, K. (org.). Identidade e diferença: a perspectiva dos estudos culturais. Rio de Janeiro: Vozes, 2000. p. 2-43.

WYNTER, S. Unsettling the coloniality of being/power/truth/freedom towards the human, after man, its overrepresentation - an argument. The New Centennial Review, East Lansing, v. 3, n. 3, p. 257-337, 2003. DOI: https://doi.org/10.1353/ ncr.2004.0015.

submetido em: 6 out. 2020 | aprovado em: 7 abr. 2021 